\title{
Interaction styles of street-level workers and motivation of clients: a new instrument to assess discretion-as-used in the case of activation of jobseekers
}

\section{Liesbeth Van Parys \& Ludo Struyven}

To cite this article: Liesbeth Van Parys \& Ludo Struyven (2018): Interaction styles of street-level workers and motivation of clients: a new instrument to assess discretion-as-used in the case of activation of jobseekers, Public Management Review, DOI: 10.1080/14719037.2018.1438501

To link to this article: https://doi.org/10.1080/14719037.2018.1438501

曲 Published online: 19 Feb 2018.

Submit your article to this journal $\pi$

Џ Article views: 2

Q View related articles $\sqsubset$

View Crossmark data 5 


\title{
Interaction styles of street-level workers and motivation of clients: a new instrument to assess discretion-as-used in the case of activation of jobseekers
}

\author{
Liesbeth Van Parys and Ludo Struyven \\ HIVA - Research Institute for Work and Society, KU Leuven, Leuven, Belgium
}

\begin{abstract}
This paper proposes a re-conceptualization and a measurement instrument for street-level workers' interaction styles. Interaction styles are a relevant lens giving insight into how discretion is used and how street-level behaviour affects clients' motivation and engagement. The re-conceptualization builds on a revision of May and Winter's interaction style concept from the perspective of the psychological self-determination theory. Data from 349 caseworkers of the Flemish employment service were collected via an online survey and analysed with factor and latent class analysis. Findings support a four-dimensional interaction style concept and reveal seven types of caseworkers along these dimensions.
\end{abstract}

KEYWORDS Street-level bureaucracy; interaction styles; active labour market policies; latent class analysis; self-determination theory

\section{Introduction}

Presenting his perspectives on the future of implementation research at the end of the 1990s, Winter (1999) made a plea to investigate the character of street-level workers' day-today interactions with their clients to move the field of research forward. In particular, he referred to the already established tradition of studying inspectors' 'enforcement styles,' that is, their degree of formalism and use of coercion. Over time, other political scientists, sociologists, and psychologists too have studied the interaction styles (also called 'motivation styles') of diverse street-level workers in the same and in other policy domains (e.g. social workers and teachers). This paper argues why it is important to continue the study of the dimensions, antecedents, and consequences of interaction styles in political sciences. In addition, to foster future knowledge accumulation and theory building, the paper presents (1) a renewed theoretical foundation for the interaction style concept and (2) a new measurement instrument to allow for more congruence between and comparability of future empirical studies.

\section{The unremitted importance of studying street-level workers' interaction styles}

Winter's (1999) argument to study inter-individual variation in interaction styles was threefold. Winter's first and main argument to study interaction styles was that 
implementation scholars should shift the focus from goal achievement to street-level behaviour. Taking goal achievement or the implementation gap as perspective for the investigation of street-level behaviour, scholars risk entangling the empirical investigation of discretion-as-used with its normative assessment. As a result, the street level is overly blamed for policy failure (Winter 1999; Hill and Hupe 2003; Barrett 2004), and the solution is short-sightedly sought in curtailing discretion (Elmore 1980; Brodkin 2016). Therefore, the normative assessment of how discretion is used by street-level workers must be distinguished from and preceded by the empirical analysis of how discretion-is-used (Winter 1999; Hill and Hupe 2003). Moreover, Winter (2003) considers the interaction style concept as a more neutral lens to streetlevel behaviour than concepts like coping which focus on the dysfunctional aspects of street-level behaviour (acknowledged by Lipsky [1980] 2010, xvii-xviii). Furthermore, the interaction style perspective to discretion-as-used can correct for an ever-stronger focus on quantitative instead of qualitative outputs under the pressure of new managerialism (Brodkin 2011). Thus, research on interaction styles is relevant in its own right to get a more complete insight in street-level workers' behaviour which goes beyond their actual decisions and coping behaviours.

In addition, Winter (1999) argued that the empirical investigation of the variation (or lack thereof) in interaction styles should contribute to knowledge accumulation and the development of middle-range theories on the factors that explain this variation (i.e. the antecedents of interaction styles). In the same vein, more recently, Hupe and Buffat (2014) proposed to investigate how the gap between action prescriptions (demands) and action resources (supply) resulting from the constellation of enabling and constraining micro, meso, and macro factors affects how street-level workers use their discretion. Brodkin (2016) proposed to take an enabling rather than a curtailing approach to discretion by investigating the conditions that are required for street-level workers to deliver qualitative and responsive services.

Though, the ultimate goal of studying interaction styles according to Winter (1999) is to learn how these styles affect clients' motivations and behaviour in order to make policy interventions more effective (i.e. the consequences of interaction styles). It is particularly this goal which has driven and still drives the research on interaction styles both in political sciences and in social psychology. Indeed, it is an ongoing debate what motivates clients to partake in policy interventions and comply with regulations and how this motivation can be affected by the street-level workers (see e.g. Schneider and Ingram 1990; Le Grand 1997; Wright 2012; Pautz, Rinfret, and Rorie 2017).

The state of the art in the next section attests to an ongoing tradition of research on interaction styles in political sciences, in particular, the study of regulatory and social policy. Yet, the state of the art also appears scattered both at the theoretical and at the methodological levels, hence impeding knowledge accumulation. In particular, scholars remain puzzled about the constitutive dimensions of street-level workers' interaction styles when it comes to how these affect their clients' motivation and behaviour. Thus, to foster the development and testing of middle-range theories on street-level workers' interaction styles and their consequences for client outcomes, (1) a theory-based re-conceptualization is required of the dimensions that constitute street-level workers' interaction styles as well as (2) a measurement instrument that allows for more congruence and comparability in the empirical investigation. 
Section 'A re-conceptualisation of street-level interaction styles by building upon the self-determination theory on human motivation' presents the theory-based reconceptualization of interaction styles by linking up the original work of May and Winter $(1999,2000)$ with social psychological self-determination theory (SDT) originally developed by Deci and Ryan (1985). The latter theoretical framework corresponds in several respects with the work of May and Winter. The interest of social psychology in motivation styles of practitioners relates to the finding that common, non-intervention-specific factors may have an evenly if not stronger influence on patients' engagement in and the success of a treatment than the actual therapeutic intervention (for an overview, see Hasenfeld [1992] 2010; Van Yperen et al. 2010). Examples of such factors which are not part of the therapy as such but of the general approach of the practitioners are the way in which they build rapport and empathy (Lambert and Bergin 1994); the extent to which they listen to patients' concerns (Moore et al. 2004); and whether they promote the therapy in a collaborative or a confrontational way (Vansteenkiste and Sheldon 2006). Recent SDT research has looked into the motivation styles of more typical street-level bureaucrats, namely teachers and their impact on students' motivation and achievement (see e.g. Vansteenkiste et al. 2005; Cheon, Reeve, and Moon 2012). Moreover, Vansteenkiste and Van den Broeck (2014) proposed to investigate the motivation styles of caseworkers at public employment service to understand how they motivate their clients in taking action to find a job.

Sections 'The re-conceptualization of interaction styles put to an empirical test' and 'Discussion' present and discuss an empirical application of the developed interaction style concept using a newly developed measurement instrument to investigate the inter-individual variation in interaction styles of caseworkers delivering employment services in a context of activation of jobseekers. The relevance of activation as case lies in the fact that it is seen as an intrinsically ambiguous practice. Activation relies on a mix of counselling and controlling activities by the caseworker vis-à-vis the clients. At the same time, active engagement and effective cooperation imply a role for clients which goes beyond the mere compliance with obligations. The empirical application allows to assess the relevance of the distinguished theoretical dimensions as well as to typify the variation in caseworkers' interaction styles along these dimensions.

The paper ends by pointing out the strengths as well as potential improvements of the presented interaction style concept and the measurement instrument (see section 'Conclusions and ways forward').

\section{State of the art of research into interaction styles}

This section sketches the state of the art of research into interaction styles that aimed at identifying the main dimensions of street-level workers' interaction styles and how these affect client outcomes (in particular, motivation and behaviour). Within political sciences, street-level workers' interaction styles have mainly been investigated in studies on regulatory and on social policy. It is important to note that the conducted literature review revealed that multiple scholars conducted research on street-level workers' interaction style(s) (dimensions) without actually coining the object of their study as such. Moreover, not all studies have eventually been published in peerreviewed journals or books. The here presented state of the art strives for exhaustion 
on the level of issues at stake rather than on the level of quantity of work published. Since the state of the art with regard to regulatory policy has been discussed at length in other publications (see e.g. May and Winter 2012; Nielsen 2016), the focus here is on the conclusions to be drawn from this state of the art. Such state of the art has not been made yet for the investigation of interaction styles in the study of social policy and will thus be discussed more at length.

\section{Research on interaction styles in the study of regulatory policy}

Overviewing the state of the art of research on enforcement styles in the study of regulatory policy, May and Winter $(2012,222)$ conclude that despite a large body of research, it remains unresolved what constitutes and affects enforcement styles and how these styles affect clients' compliance. A first ongoing debate relates to the question whether enforcement styles are one- or multidimensional. A unidimensional interpretation distinguishes a punitive, rule-oriented, and strict enforcement style from an accommodative and conciliatory one. However, other scholars have argued that the two ends of this continuum are multifaceted and that regulators' actions with regard to these facets are too diverse to consider them as relating to one end. For instance, Hutter (1989) identified two subtypes within the accommodative style: a persuasive and an insistent strategy - the latter being 'less benevolent and less flexible' than the former. Furthermore, drawing a typology of the enforcement styles applied by the municipal regulators vis-àvis farmers, May and Winter (2000) find that formalism and coercion do not necessarily go hand in hand.

A second ongoing debate relates to how inspectors' enforcement styles affect compliance (Bardach and Kagan [1982] 2002; May and Winter 2012). A shift is remarkable over time: whereas it was formerly assumed that citizens or firms can only be motivated to comply with regulations by use of coercion, motivation is now considered as a much more complex phenomenon downsizing the relative importance of coercive approaches and favouring more cooperative approaches (Pautz, Rinfret, and Rorie 2017). Hence, the interest in which individual- and organizationallevel factors foster cooperation among regulator and regulatees is growing (Nielsen 2016; Pautz, Rinfret, and Rorie 2017).

\section{Research on interaction styles in the study of social policy}

In the study of social policy, it was the shift from passive towards activating labour market policies that triggered research on the extent to which and how exactly caseworkers combine their cooperative guidance role and policing role. A first set of social policy studies consists of those in which the conceptualization of interaction styles is developed inductively by analysing data gathered via observations and indepth interviews. To start, Benarrosh (2006; discussed by Dzimira 2007) distinguished four types of caseworkers at the French public employment service ANPE (Agence nationale pour l'emploi [National Agency for Work]) along two axes: (1) the degree of conditionality and (2) the degree of adaptation of the client to the organization. The ANPE caseworkers combine (non-)conditionality and (non-)personalization once symmetrically and then non-symmetrically.

Building on a survey among 320 caseworkers and 126 interviews with caseworkers, teachers, and participants, Djuve and Kavli (2014) identified two ideal types among 
caseworkers in the activating Introductory Programme for immigrants in Norway. So-called 'clerks' act strict and rule-bounded in their contacts with clients, while socalled 'carers' are more flexible and open to the client. While the former tend to overrule choices of clients, the latter are more ready to adapt to the client.

McDonald and Marston (2005) analysed twelve in-depth interviews with caseworkers and twelve with clients from profit and non-profit providers of employment services in the Job Network in two states in Australia. They identified three modes of authority used by the caseworkers in their contacts with clients aimed at altering the (self-)conduct of clients: empathetic authority, pedagogic authority, and coercive authority.

Last, Bruhn and Ekström (2017) observed and inductively analysed the telephone conversations of caseworkers at the Swedish Board for Study Support with students applying for loans. They found that despite the fact that the setting is rather highly rule-governed caseworkers invoked and negotiated rules in various ways bending more or less to clients' wishes and showing more or less empathy even in similar situations.

A second set of (mainly quantitative) social policy studies links the variation in interaction styles to outcomes at the client level. Some of these outcomes are more directly within the street-level bureaucrats' reach (e.g. engagement and compliance), whereas others are more distant (e.g. transition to employment). Weatherall and Markwardt (2010) who built further on the conceptualization and the measures of the interaction styles concept developed by Winter (2003; see section 'A re-conceptualization of street-level interaction styles by building upon the self-determination theory on human motivation') studied the influence of caseworkers' interaction styles on their unemployed clients' transitions from unemployment. Applying multinomial logit regression, the authors find that keeping professional distance (opposite of empathy) has a negative effect on the transition to employment (compared to transitions to other labour market statuses) both for insured and for non-insured clients. Neither formalism nor coercion affected the transition to employment of the two groups of clients. Though, in comparison with the socio-economic characteristics of the clients, caseworker behaviour is found to explain rather a minor part of the variation in clients' transitions.

Riccio and Hasenfeld (1996) investigated the role of personalized attention and sanctions as two strategies to elicit compliance in mandatory welfare-to-work GAIN programmes in the twenty local offices of six purposefully selected counties in California at the end of 1980s. Personalized attention is understood as disposing of time to get to know clients and their situation and acting as helper rather than as rule enforcer. This score is based upon a nine-item scale in the staff survey. So as to measure the use of sanctions, the researchers looked at the formal penalty rate, i.e. 'the proportion of recipients ever placed in conciliation, sanctioned, or slated for sanctioning within the first 11 months after attending a GAIN orientation' (523). The data consist of a share of the 23,000 single parents that were randomly assigned to or excluded from the GAIN programme. The researchers found a negative correlation between the formal penalty rate of the twenty local offices and the average scores of offices on the personalized attention scale. There is also a negative correlation between the formal sanction rate and the share of recipients that participated once in a GAIN activity as well as the share that participated enduringly, whereas there is a positive correlation between personalized attention and the share of short and enduring participation. However, the size of the 
correlation drops to a level that is no longer statistically significantly different from zero if one office with an extremely low participation rate is included.

Behncke, Frölich, and Lechner (2010) conducted a quantitative study on the dual role of caseworkers in the regional employment offices in Switzerland. They first measured the degree to which caseworkers are ready to 'cooperate' with clients' wishes using a one indicator question 'How important do you consider the cooperation with the jobseeker, regarding placements in jobs, and assignment of active labour market programmes?' (three answer categories). In a second step, they investigated the relation between the degree of cooperation and the degree of policing. They found that less cooperative caseworkers attach more importance to control and sanctions than to counselling and are more likely to put pressure on their clients by assigning them to programmes and by controlling their availability for work. The statistical analyses of client-caseworker matched data showed that caseworkers who put less emphasis on a co-operative relationship with their clients increase their employment chances in the short and medium term.

Bloom, Hill, and Riccio (2003) looked into the effect of the emphasis that caseworkers put on (1) quick job entry, (2) personalized client attention, and (3) close client monitoring on the future earnings of clients after participating in a welfare-towork programme compared to a control group of non-participants. These interaction style dimensions were measured with a survey among staff but aggregated at office level for analysis. The researchers further controlled for caseload size, client characteristics, and the local economic environment by applying a multilevel statistical design. The sample consisted of 69,399 programmes (GAIN, NEWWS, and PI) and control group members and 1,225 caseworkers and 194 supervisors from local offices completed the survey. A positive effect on earnings is found for emphasis on quick job entry and personalized client attention, but high caseloads undermine programme effectiveness.

Last, Toerien et al. (2015) explained the higher performance in job placements of the private Employment Zone offices compared to the public Job Centre Plus offices in the UK by pointing to the differences in 'advisory styles.' The former caseworkers are found to be 'more collaborative, directive, proactive, positive and challenging' (15, original emphasis). Hence, they are believed to be better at balancing their dual role of counsellor and enforcer such that the clients have a sense of sovereignty in the process and experience the exercised control as in their own interest. Their findings are based on inductive conversation analysis of eighty-eight video and audio recordings of advisory interviews between caseworkers and clients; forty-eight from Jobcentre Plus (JCP) and forty from Employment Zone (EZ) offices.

\section{Conclusion on the state of the art}

Overall, the presented state of the art in both regulatory and social policy studies points to a myriad of interaction style conceptualizations based to a limited extent on theoretical frameworks on the one hand and diverse inductive empirical analyses on the other. A large set of potential interaction style aspects comes to the fore, but it remains unclear to what extent they are extreme ends of one dimension or form dimensions in their own right. Moreover, the state of the art attests to the need for more insight into how different interaction style aspects affect client outcomes. Indeed, the studies reported above point in different directions. For instance, Behncke, Frölich, 
and Lechner (2010) conclude that employment chances of clients are increased if caseworkers put less emphasis on cooperation, whereas Toerien et al. (2015) 2015 believe that the higher performance in job placements in the private versus the public offices is thanks to the more collaborative approach of the former. While the state of the art provides evidence that interaction styles do matter for client outcomes, the study of Weatherall and Markwardt (2010) suggests that the role of caseworkers in the larger set of factors affecting client outcomes is relatively minor.

\section{A re-conceptualization of street-level interaction styles by building upon the SDT on human motivation}

This section presents the original interaction style concept as it was developed by May and Winter $(1999,2000)$ as well as the concept of 'motivation styles' as it is developed in the SDT on motivation. Next, it is argued why the work of May and Winter has been valuable and how linking it up with the psychological concept of motivation styles leads to an improved theory-based conceptualization.

\section{The original work of May and Winter}

May and Winter $(1999,2000)$ developed a concept and measurement instrument to investigate how municipal inspectors enforce agro-environmental regulations upon farmers in Denmark. Applying a principal component analysis of the survey responses of inspectors from 216 municipalities with regard to the character of their interactions with farmers, they distinguished two enforcement style dimensions: the degree of formalism and the degree of coercion. Whereas the former points to the rigidity and formality of the interaction, the latter relates to the severity of the use of threats. Later on, Winter (2003) enlarged the concept of enforcement styles by adding a third dimension - degree of empathy - so as to make it applicable to social policies.

May and Winter's conceptualization of street-level bureaucrats' 'enforcement styles' is based on an a priori developed theoretical framework on human motivation for which they built to a large extent on the work of Burby and Paterson (1993; Winter and May 2001). The latter framework is based on social control theory which distinguishes the following bases for client compliance with regulatory policy: incentives, norms/morals, and coercion (Burby and Paterson refer to Etzioni 1961; Wood 1974; Balch 1980). Thus Winter and May $(2001,676)$ distinguish three 'not necessarily mutually exclusive' motivations to comply: calculated, normative, and social motivations. Individuals' motivations to comply with a regulation are considered as calculated if they are the result of a weighing of the costs and benefits of compliance so as to choose the action with the highest net return. Building on Becker (1968), Winter and May (2001, 676-677) expect that the following aspects affect these calculations: the likelihood of detection (which increases when the frequency of inspection increases), the speed, certainty and size of the sanctions, and the cost of compliance. A second kind of motivation for compliance according to Winter and May (2001) is internalized normative commitments. Regulated entities are expected to comply if they experience a moral sense of duty and if they agree with the importance (reasonable and fair) of the regulation. Social motivation is defined as the desire of the regulated to earn the approval and respect of significant people with whom they 
interact' which may lead to normative motivations in the longer run through socialization (authors refer to Grasmick and Bursik 1990).

Winter and May (2001) expect that regulators' degree of formalism and coercion affect social motivation because they shape social expectations. They do not expect a direct relation between the degree of formalism and coercion on the one hand and calculated and normative motivations on the other.

\section{The social psychological SDT}

The social psychological SDT in turn is a macro-theory of motivation, emotion, and personality which has been under development for more than 40 years and builds on the seminal work of psychologists Deci and Ryan $(1985,2000)$. SDT subscribes to positive psychology as it focuses on human strengths and positive outcomes rather than adopting a disease model (Deci and Vansteenkiste 2004).

The basic assumption of SDT is that people are by nature proactively inclined towards psychological growth and integration (Deci and Ryan 2000). Though for these inherent processes to continue, people must experience support for three basic psychological needs from their (social) environment. People's need for autonomy is 'the desire to experience personal ownership over one's actions, thoughts, and emotions and to engage in an activity with a sense of volition and psychological freedom' (Vansteenkiste and Van den Broeck 2014, 2). The need for relatedness is 'the desire to develop satisfying and deeply anchored relationships' and the need for competence 'the desire to feel effective in what one does and in mastering new skills in the process' (2-3).

SDT research showed that there is a direct relation between the extent to which their basic needs are satisfied/frustrated and the quality of people's motivations (Deci and Ryan 2000). The quality of motivation is a continuum ranging from controlled to autonomous motivation. ${ }^{1}$ Ordered by degree of strength, autonomous motivation for an activity results from the joy of or interest in the activity in itself; the personal conviction that the activity is useful; or an agreement with an underlying norm. In contrast, controlled motivation implies that people engage in an activity due to internal (e.g. shame or guilt) or external pressure (e.g. a sanction or reward). Conditions that support people's basic needs will foster autonomous motivation, whereas need frustrating conditions will undermine this motivation.

In terms of SDT thinking, and applied to the ambiguous context of employment activation, Vansteenkiste and Van den Broeck (2014, 14-15) state that the following is required for an employment service caseworkers' interaction style to be basic need supportive $^{2}$ :

- autonomy supportive: allowing for participation and dialogue, provide choice, being open for the perspective of the client, and giving meaningful rationale for limitations of choice

- competence/structure supportive: setting out rules and expectations clearly, making stepwise realistic plans, and offering support and realistic feedback

- relatedness supportive: showing a concern with the clients' situation.

Yet, caseworkers may also dissatisfy or even frustrate the basic needs of their clients, for instance, when they act in a controlling (instead of an autonomy supportive) way. A controlling style implies threatening with external consequences (e.g. 
sanctions) or the exertion of internal pressure by using controlling language (i.e. overly pointing to personal responsibility).

\section{Towards a renewed conceptualization of interaction styles}

Looking at the conceptual work done by May and Winter from the perspective of SDT reveals striking similarities. Yet, the comparison also shows that the work of May and Winter can be further improved in three respects (see Table 1).

First, both theoretical frameworks distinguish multiple motivational sources. Compared to SDT, May and Winter overlook a key motivational source: intrinsic motivation (see first row of Table 1). To recall, this is the ultimate form of autonomous motivation as people engage in activities out of sheer pleasure.

Second, SDT suggests additional relevant interaction style dimensions (see second row of Table 1). To start, the dimension 'coercion' in May and Winter's framework parallels with the notion of autonomy frustration by threatening with sanctions in SDT. Autonomy frustration in SDT is broader though in that it also comprises endogenous pressure in the form of controlling, disciplining language that aims at triggering a sense of shame or guilt within the client. Moreover, since Winter and May (2001) overlooked the possibility that clients can be intrinsically motivated to engage in services, they did not think off an autonomy supportive interaction style dimension, i.e. offering genuine choice and justifying limitation of choice. Next, the dimension 'formalism' in May and Winter's framework partly overlaps with 'competence support' in SDT as both imply that the street-level bureaucrat clearly sets out the rules and expectations. Competence support in SDT is broader though as it also entails that street-level

Table 1. Comparison of motivations and the interaction style dimensions which affect them according to, respectively, Winter and SDT.

\begin{tabular}{|c|c|c|}
\hline & May and Winter & Revision based on SDT \\
\hline Motivations & $\begin{array}{l}\text { - Calculated motivation } \\
\text { - Social motivation } \\
\text { - Normative sense of duty }\end{array}$ & $\begin{array}{l}\text { Degree of internalization: } \\
\text { - External pressure } \\
\text { - Introjected regulation } \\
\text { - Identification } \\
\text { - Internalization } \\
\text { - Intrinsic (passion) }\end{array}$ \\
\hline $\begin{array}{c}\text { Interaction style } \\
\text { dimensions }\end{array}$ & $\begin{array}{l}\text { - Empathy } \\
\text { - Formalism }\end{array}$ & $\begin{array}{l}\text { (1) Support for basic human needs: } \\
\text { - Autonomy support: open to perspective, providing } \\
\text { choice, and justification for limitation of choice } \\
\text { - Relatedness support: empathy and availability } \\
\text { - Competence support: clear expectations } \\
\text { + stepwise, tailored to capacities, and strengthening } \\
\text { by linking-up and giving feedback } \\
\text { (2) Frustration of basic human needs: Autonomy } \\
\text { frustration: } \\
\text { - External pressure by threatening with external } \\
\text { consequences } \\
\text { - Internal pressure by controlling/guilt/shame-indu- } \\
\text { cing language }\end{array}$ \\
\hline
\end{tabular}


bureaucrats support their clients by proceeding stepwise and by strengthening their clients with realistic feedback. In addition, formalism implies autonomy frustration in those cases where bureaucrats apply rules so strictly that there is no room left for the clients' perspective. May and Winter's third dimension, empathy, clearly matches with the dimension 'relatedness support' in SDT.

In a third respect, SDT helps to completely spell out how motivation may be driven by interaction styles - an aspect which is missing in the work of May and Winter (see above). Interaction styles that are supportive of people's basic needs foster autonomous motivation, whereas styles that frustrate basic needs may lower autonomous and trigger controlled motivation.

To conclude, the renewed conceptualization distinguishes three pairs of interaction style dimensions that are expected to affect client motivation and behaviour, that is, the degree to which street-level bureaucrats act in an autonomy supportive versus controlling way ( $1 \mathrm{a} \& \mathrm{~b})$, a competence supportive versus chaotic way $(2 \mathrm{a} \& \mathrm{~b})$, and a relatedness supportive versus a cold way $(3 \mathrm{a} \& \mathrm{~b})$ vis-à-vis their clients. The first pair is put to an empirical test in the next section.

\section{The re-conceptualization of interaction styles put to an empirical test}

Time has come to put the theoretical re-conceptualization of interaction styles to the test in a real empirical case. First and foremost, the aim of the empirical test case presented below was to develop a valid instrument to measure interaction styles in the field of social policy, in particular labour market activation policy. In addition, the empirical test case aimed to tackle a theoretical and empirical issue. Theoretically, a long-lasting debate in the field of regulatory policy relates to the question whether enforcement styles are one- or multidimensional (see section 'State of the art of research into interaction styles'). Similarly, among self-determination scholars, there is a debate as to whether or not an autonomy supportive and controlling style are two opposite ends of one continuum. In several studies on the interaction styles of teachers, a statistically significant though substantially moderate negative correlation was found between these two dimensions (see Reeve et al. 2014). This suggests that teachers consider both sets of behaviours as compatible rather than as mutually exclusive. Thus, in both fields, there is growing evidence for a multidimensional concept which we expect to be confirmed again here. The empirical issue relates to the question whether the conceptualization allows to identify interpersonal variation in street-level bureaucrats' interaction style. In other words: can different types of interaction style be distinguished among the studied street-level bureaucrats?

To tackle these questions, the empirical application of the interaction style construct presented here focuses on one of the three theoretically distinguished pairs of interaction style dimensions: the dimensions autonomy support and control. Of the three basic psychological needs, autonomy is considered the most crucial in SDT. Moreover, beyond the field of psychology too, autonomy has been pointed out as constitutive for human functioning and motivation (see e.g. Doyal and Gough 1984; Sen 1999 discussed in Crocker and Robeyns 2010). At last, the degree of choice (cf. 'personalization') and coercion are main themes in the studies on regulatory and social policy mentioned in the literature overview above. 
The empirical test case is the implementation of labour market activation policy by caseworkers in the Flemish public employment service (VDAB). At the policy level, the Flemish case fits the theoretical framework of the study well as it is not a harsh work first activation policy aimed at 'disciplining' unemployed people (cf. Soss, Fording, and Schram 2011 for the US; Caswell and Larsen 2017 for Denmark). Instead, the Flemish government and social partners agreed in the Career Agreement of 2012 to strive to balance activation and protection; unemployed people's preferences and labour market needs; and quick and sustainable job placement. Moreover, the study was conducted against the background of the consolidation of a major reform process in which VDAB's caseworkers were granted a higher degree of discretion in their daily work to assess client needs and assign tailored help, tasks, and follow-up meetings. The steering of and within VDAB is inspired by new managerialism (Janssen 2006) but not to the extent that the steering of caseworkers takes the form of 'disciplining' as it is described for instance in the US (see Soss, Fording, and Schram 2011) and Denmark (see Caswell and Larsen 2017). Furthermore, as a result of the recent transfer of authority from the federal state to the regions, caseworkers' role in monitoring and sanctioning clients has been reinforced and places them unprecedentedly in a double and potentially conflicting role. To be precise, the caseworkers must at the same time support their clients by giving advice and help in their job search process and monitor their clients' job search efforts and eventually 'transmit' them to the internal control section in case their efforts are deemed insufficient to remain eligible for the unemployment benefit. $\mathrm{VDAB}$ is a relevant case in international perspective as it serves both unemployment benefit recipients and social welfare recipients and proactively tackles labour market and managerial and service delivery challenges common for public employment services (Struyven and Van Parys 2014).

In order to study the interaction styles of the VDAB caseworkers, an online survey was conducted from 22 August until 14 October 2016. Among the 1,436 identified frontline staff working at VDAB identified in the staff database, at most 1,249 belong to the described group of caseworkers. Among them, 595 participated in the survey (response rate: 48 per cent) and 394 completed the survey (full response rate: 32 per cent). In line with the tradition of survey-based research on interaction styles (see section "A re-conceptualization of street-level interaction styles by building upon the SDT on human motivation'), the instrument developed to measure the caseworkers' interaction styles consists of a battery of Likert items. The battery was constructed such that it contains multiple items per interaction style dimension of interest. In total, the battery comprises twenty-six items to gauge the extent to which caseworkers act in an autonomy supportive and/or controlling way. To be precise, eight items related to the exercise of psychological control (by triggering internal or external pressure); five related to the exercise of behaviour control; five to offering choice; four to looking from the clients' perspective; and five to justifying limitation of choice. The items were selected and adapted from a long list verified stepwise by an SDT expert and an activation expert and through an in-depth pretest with caseworkers and a team leader. The caseworkers had to answer how often they applied the behaviour described by each item on a 5-point scale with $1=$ (almost) never; $2=$ more not than often; 3 = just as much (neutral middle point); 4 = more often than not; and $5=$ (almost) always. A frequency scale is preferred to an agreement scale since the aim is to measure behaviour and not attitudes. 
Applying subsequently exploratory and confirmatory factor analysis (robust maximum likelihood; with maximum 1,000 iterations and convergence criterion 0.500D04) in Mplus ${ }^{\circledR}$ (version 7; Muthén and Muthén [1998] 2017), it was tested to what extent the empirical factor structure of the caseworkers' answers reflected the theoretically expected (sub)dimensions of the interaction style construct. The solution pointed to the following structure of four correlating factors (fit measures: $\mathrm{Chi}^{2}=170.93, d f=84, p=0.00 ; p$ (the root mean square error of approximation $($ RMSEA $) \leq 0.05)=0.26$; the comparative fit index $(\mathrm{CFI})=0.93$; Tucker-Lewis index $(\mathrm{TLI})=0.92)$ :

(1) use of behavioural control (three items) - example item: I make efforts to find out whether the unemployed clients did what we had agreed upon

(2) use of psychological control (four items) - example item: I emphasize that unemployed clients have the duty to make efforts in exchange for the benefit

(3) offering of choice (five items) - example item: I allow the unemployed clients to decide things for themselves

(4) justifying limitation of choice (three items) - example item: When I impose something upon unemployed clients, I explain its use

The reliability of these four scales and thus the multidimensionality of the interaction style construct were confirmed by the confidence intervals (CIs) of the Raykov reliability estimates ${ }^{3}$ (see Table 2 ) computed in RStudio ${ }^{\circledR}$ ( $\mathrm{R}$ version 3.3.2; RStudio Team 2015).

Looking at the average scores of the caseworkers on the scale items, the caseworkers scored 3.64 on the psychological control scale; 4.34 on the use of behavioural control scale; 3.48 on the offering of choice scale; and 4.40 on the justifying limitation of choice scale. In other words, on average, caseworkers 'more often than not' use behavioural control and justify limitation of choice. On average, the caseworkers are less eager ('just as much' to 'more often than not') to use psychological control and to offer choice. As expected theoretically, offering choice correlates (slightly) positively with justifying the limitation of choice (95 per cent CI: 0.04-0.25) and clearly negatively with psychological control (CI: -0.19 to -0.39$)$. No correlation is found between offering choice and behavioural control (CI: -0.14 to 0.07$)$. Moreover, on average, positive correlations are found among behavioural and psychological control (CI: $0.32-0.50$ ), between psychological control and justifying the limitation of choice (CI: 0.26-0.44), and between behavioural control and justifying the limitation of

Table 2. The Raykov reliability estimates of the scales measuring caseworkers' application of the three interaction style dimensions.

\begin{tabular}{lccccccc}
\hline & $\begin{array}{c}\text { No. } \\
\text { of } \\
\text { Items }\end{array}$ & $\begin{array}{c}\text { Raykov } \\
\text { reliability } \\
\text { estimate }\end{array}$ & $\begin{array}{c}\text { Standard } \\
\text { error }\end{array}$ & $\begin{array}{c}\text { Estimate/ } \\
\text { standard } \\
\text { error }\end{array}$ & $\begin{array}{c}\text { Two- } \\
\text { tailed } \\
p \text {-value }\end{array}$ & $\begin{array}{c}\text { Lower } \\
\text { bound } \\
95 \% \mathrm{Cl}\end{array}$ & $\begin{array}{c}\text { Upper } \\
\text { bound } \\
95 \% \mathrm{Cl}\end{array}$ \\
\hline $\begin{array}{l}\text { Scale } \\
\begin{array}{l}\text { Controlling dimension } \\
\text { Use of behavioural control }\end{array}\end{array}$ & 3 & 0.75 & 0.04 & 21.26 & 0.00 & 0.68 & 0.82 \\
$\begin{array}{l}\text { Use of psychological control } \\
\text { Autonomy supportive dimension }\end{array}$ & 4 & 0.77 & 0.02 & 32.98 & 0.00 & 0.73 & 0.82 \\
$\begin{array}{l}\text { Offering choice } \\
\text { Justifying limitation of choice }\end{array}$ & 5 & 0.78 & 0.02 & 38.12 & 0.00 & 0.74 & 0.82 \\
\hline
\end{tabular}




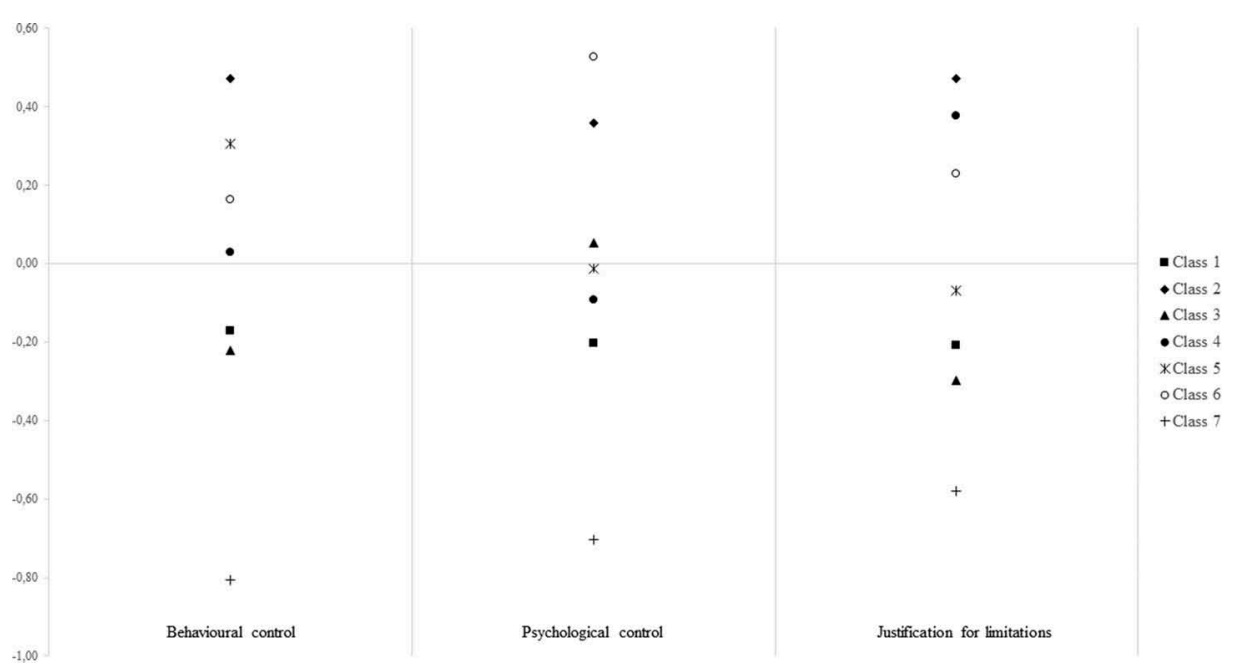

Figure 1. The typology of interaction styles among the caseworkers of the Flemish public employment service derived from the factor scores of the interaction style dimensions with latent class analysis.

choice (CI: $0.66-0.77)$. The fact that the latter correlation is stronger than the one but last is logic since the more caseworkers limit their clients' behavioural options, the more occasions they have to justify the imposed limitations.

Next, latent profile analysis (Vermunt and Magidson 2009) was conducted in the programme Latent Gold ${ }^{\circledR}$ to find out whether these averages hide differences in how caseworkers combine scores on the four dimensions. This analysis learned that the caseworkers do not sufficiently differ in the degree to which they offer choice to their clients to distinguish different profiles. Instead, seven interaction style types could be identified among the caseworkers along the three remaining dimensions (see Figure 1).

Among the seven distinguished classes, class 2 (\#60) and class 6 (\#26) represent the caseworkers who make the most use of psychological control and who are among the three classes making the most use of behavioural control. In addition, they are among the three classes who justify the limitation of choice the most but also among the classes who are the least eager to provide for choice. In practice, unemployed clients may experience class 2 caseworkers rather as 'severe but just' and class 6 caseworkers rather as pressuring in an autonomy frustrating way because the latter put more emphasis on psychological control compared to the emphasis on behavioural control and the justification for the limitation of choice. Class 7 (\#24) at the bottom of the figure comprises caseworkers whose approach tends towards 'laissez-faire.' These caseworkers are the least eager to control their clients behaviourally and psychologically and to justify limitation of choice. The other four classes represent relative moderate interaction styles. Class 4 (\#52) is a particular type since compared to classes 1, 3, and 5 (resp. \#61, \#43 and $\# 45$ ), the former caseworkers are more eager to justify limitations of choice. This is also the class with the highest score on the offering choice dimension and is therefore considered as the most autonomy supportive. 


\section{Discussion}

These findings shed a more in-depth street-level light on how the VDAB-caseworkers deal with two traditional dilemmas faced by street-level workers in welfare state institutions, that is, between autonomy and control and between equality and responsiveness (Lipsky [1980] 2010; Hjörne, Juhila, and Van Nijnatten 2010; Struyven and Van Parys 2014). Although the double task in activation to give more autonomy by providing for choice on the one hand and to control clients' efforts on the other is often thought as irreconcilable, the findings show that the caseworkers balance the offering of choice, the justification of limitations of choice, and the exertion of behavioural control and psychological control in different ways. Whereas the 'laissez-faire'-type of caseworkers in the sample put little effort in justifying limitations of choice and exert little behavioural and psychological control, another group of caseworkers exerts both forms of control very often. Overall, the caseworkers in the sample could provide more room for choice. Furthermore, the identification of different types of interaction styles emphasizes the importance of distinguishing two qualitatively different types of control, that is, behavioural control which implies monitoring of clients' behaviour on the one hand and psychological control which implies pressure in the form of e.g. threatening language on the other. It is only the latter more disciplinary type of control that is expected to undermine clients' autonomous motivation to engage in the activation trajectory according to the SDT. If policymakers and managers want to foster clients' autonomous (rather than controlled) motivation to partake in service delivery, SDT prescribes that caseworkers should be learned and encouraged to apply a basic needs supportive interaction style (offering manageable choice; justifying limitation of choice; and no psychological control). This does not imply a 'laissez-faire' approach (Vansteenkiste and Van den Broeck 2014). On the contrary, caseworkers can apply behavioural control if they set realistic expectations and are clear about the consequences of not acting upon them.

When it comes to the dilemma between equal treatment and responsiveness, the findings show that clients in similar situations may not only be treated differently in terms of what they get but also in how they are treated. Policymakers and public service managers should be well aware of this variation at the street level (even within a single organization) and tackle it upfront. Given the fact that interviewed VDAB-caseworkers indicated that they have been overburdened with a growing number of guidelines, the solution is not a curtailment of discretion by adding rules and guidelines. Rather clearer guidelines, decision supporting targeting tools, and case-based intervision are recommended to achieve more consistency in caseworkers' activation style.

\section{Conclusions and ways forward}

In sum, this paper argued to put the study of street-level workers' interaction styles higher on the agenda of policy implementation and street-level bureaucracy research. Interaction styles are a crucial aspect of street-level workers' behaviour (discretion-as-used) as it refers to the characteristics of how they interact with their clients that are expected to affect their clients' motivations and behaviours. In neither strands of political sciences, the concept is new. Yet the analysis of the 
state of the art revealed that the concept needs a firmer theoretical basis as well as consistency in its measurement in order to accumulate knowledge on the variety in street-level workers' interaction styles and their impact on client motivation and behaviour. To overcome this state of affairs, a renewed conceptualization of interaction styles was proposed building on the original work of May and Winter $(1999,2000)$ and linking it up with the social-psychological SDT (Deci and Ryan 1985). Confronting the interaction style construct of May and Winter with this macro-theory on human motivation has revealed the strengths of the former construct but also pointed to some overlooked aspects of interaction style dimensions. The renewed conceptualization distinguishes three pairs of interaction styles dimensions, that is the degree to which street-level bureaucrats act in an autonomy supportive versus controlling way (1a\&b), a competence supportive versus chaotic way $(2 \mathrm{a} \& \mathrm{~b})$, and a relatedness supportive versus a cold way $(3 \mathrm{a} \& \mathrm{~b})$ vis-à-vis their clients.

The first pair of dimensions was put to an empirical test. Two sub-dimensions for each dimension were investigated: the degree to which caseworkers offer choice (1a1) and justify the limitation for choice (1a2) and the degree to which caseworkers exert behavioural (1b1) and psychological control (1b2). The data collected among the caseworkers of the Flemish public employment service allowed to validate the developed survey-based measurement instrument - a Likert-item battery consisting of 15 items related to the four sub-dimensions. Moreover, the confirmatory factor analysis and latent profile analysis shed light on a theoretical and empirical issue. At the theoretical level, the data confirm that autonomy support and control are not two ends of the same continuum but distinct interaction style dimensions which are considered as compatible by at least part of the caseworkers but not by others. Moreover, the findings point out that a qualitative distinction has to be made between behavioural and psychological control. Empirically, seven types of interaction styles could be identified among the caseworkers attesting to the fact that even within the same organization considerable variation can be found among caseworkers when it comes to how they interact with (and thus motivate) their clients. Hence, the data shed light on how the Flemish caseworkers deal with two classical dilemmas in street-level social work. First, overall, the Flemish caseworkers balance autonomy support and control attesting to a moderate activation regime. Comparative research with the new measurement instrument in other countries may reveal other more permissive or disciplinary activation regimes. Second, the identification of seven types of interaction styles among the Flemish caseworkers within a single organization raises a concern with regard to the balance between responsiveness vis-à-vis clients and their right to equal treatment. Clearer guidelines and regular case-based intervision are recommended to achieve more consistency in caseworkers' activation style.

The following tasks for future research are recommended. First, while the interaction styles construct is supposed to be applicable and relevant to many policy areas, the measurement instrument was developed to be applied within the employment activation domain. This instrument is applicable to other employment activation settings, but not necessarily to other policy domains. Theoretically, it remains to be tested whether the multidimensional construct and the correlations found between (sub-)dimensions are also confirmed in empirical studies in other policy domains. Moreover, the interaction style dimensions competence support/chaos and relatedness support/coldness are to be included in new instruments. 
Second, future research could focus on the development of additional complementary measurement instruments. The strengths of the survey-based instrument presented here are that it is deductively developed to empirically verify the underlying theoretical construct and that it allows for systematic data collection across a large sample. Inherent to selfreported interaction styles is that answers are susceptible to social desirability and biased self-assessment. To moderate these tendencies, a frequency instead of an agreement answer scale was chosen here. An alternative way to assess interaction styles is through observation. That is, using a rating card of interaction style dimensions one or multiple researchers can (in)directly observe and assess street-level bureaucrats' behaviour. Yet, this approach is time-consuming and hence costly. Either way, there is the challenge to infer interaction styles from behaviours in particular cases and situations. In surveys, this requires selfreflection and abstraction from the respondent; in observations, it requires a sufficiently diverse number of rating occasions per caseworker and observer. A third way could consist of a survey-based diary study.

Ultimately, the goal of studying interaction styles is to foster future research on (1) the explanatory factors of variation in interaction styles within and between street-level workers and (2) the causal relationship between these behaviours and the policy outcomes at client level. When it comes to intra-individual differences, it remains to be tested to what extent interaction styles are a fixed personal trait in analogy with personality (Beckmann and Wood 2017). If a kind of basic interaction style tendency can be identified within individual caseworkers, the question rises to what extent caseworkers' actual behaviour varies from this base as a result of circumstantial factors. Indeed, changing working conditions may force caseworkers to deviate from their basic interaction style. Equally so the characteristics and behaviour of clients and particularly the balance of power and interests in the clientstreet-level worker relation (Nielsen 2016) may trigger deviation. In order to answer these questions, the study of inter-individual differences may be complemented with the study of intra-individual differences.

In order to shed light on the (non-)variation in interaction styles between street-level workers, the notion of the 'public service gap' (Hupe and Buffat 2014) is a promising heuristic device, particularly since it distinguishes between objective situations and how they are subjectively experienced. For instance, street-level workers in similar 'objective' situations may apply different interaction styles because of e.g. their varying coping strategies and capacities, different motivations (Vandenabeele 2007), and/or different degrees of policy alienation (Tummers, Bekkers, and Steijn 2009).

The second goal to investigate how interaction styles affect client outcomes at first sight overlaps with the goal of policy evaluation studies. Though as Winter (1999) argues implementation and street-level studies have a complementary role to play. The design and methods applied in these studies assume that these interventions are assigned to clients by caseworkers in a standardized and neutral way. Yet, as this paper has shown realistic evaluation, studies should account for the diversity in the interaction styles of the caseworkers involved in delivering activation towards their unemployed clients.

\section{Notes}

1. Next to controlled and autonomous motivation, the self-determination theory also distinguishes 'a-motivation.' This state implies that the individual has no intention to act (Ryan et al. 2011). 
2. To be sure, SDT does not suggest that caseworkers apply a supportive interaction style in order to elicit compliance as a way of manipulation. A genuine need supportive style implies that the choice to engage or not is ultimately left to the client but that the client is well informed about the consequences of each option. However, it is expected that clients will be more autonomously motivated to engage if they experience choice, competence, and respect.

3. Like Cronbach alpha, the Raykov rho test compares the share of true score variance to the total observed variance in the set of measures (Raykov 2004). The Raykov test is chosen here because an important assumption of the Cronbach alpha test - that the factor loadings of the indicators on the latent factor are equal (tau equivalence) - is violated in the case of these data.

\section{Acknowledgements}

The authors wish to thank the reviewers for their thorough and pertinent feedback. The authors are grateful to Aurélien Buffat, Hal Colebatch, Gitte Sommer Harrits, Michael Hill, Peter Hupe, Steven Maynard-Moody, Marie Østergaard Møller, Frits Sager, Lars Tummers, and Bernardo Zacka for their feedback on ideas in development presented at conferences, at seminars, in the $\mathrm{PhD}$ manuscript, and on draft versions of this paper. A warm 'thank you' goes out to psychologists Anja Van den Broeck and Maarten Vansteenkiste for their valuable feedback at different stages of measurement instrument development.

\section{Disclosure statement}

No potential conflict of interest was reported by the authors.

\section{Funding}

This work was supported by the Fonds Wetenschappelijk Onderzoek [PhD Fellowship] and VIONA - the Flemish Interuniversity Research Network for Labour Market Reporting [Research and Development Assignment].

\section{Notes on contributors}

Liesbeth Van Parys is a senior researcher associate at HIVA - Research Institute for Work and Society at KU Leuven. She holds a PhD in Social Sciences from the KU Leuven. Her research focuses on the design, implementation, and evaluation of labour market policies which she approaches from a political scientist perspective with special interest in linking up with social psychology. She is acquainted with different quantitative and qualitative approaches to data collection and analysis.

Ludo Struyven is a professor in Sociology of Work and Education at the KU Leuven and head of the Research Group on Education and Labour Market at HIVA - Research Institute for Work and Society at KU Leuven. He is also a visiting professor at Université Saint-Louis, Brussels. His research areas include labour market dynamics, employment services, labour market institutions and reform, organizational sociology, and governance studies.

\section{References}

Balch, G. I. 1980. "The Stick, the Carrot, and Other Strategies: A Theoretical Analysis of Government Intervention.” Law \& Policy 2 (1): 35-60. doi:10.1111/j.1467-9930.1980.tb00203.x.

Bardach, E., and R. A. Kagan. [1982] 2002. Going by the Book: The Problem of Regulatory Unreasonableness. New Brunswick: Transaction Publishers.

Barrett, S. 2004. "Implementation Studies: Time for a Revival? Personal Reflections on 20 Years of Implementation Studies." Public Administration 82 (2): 249-262. doi:10.1111/j.0033-3298.2004.00393.x. 
Becker, G. 1968. "Crime and Punishment: An Economic Approach.” Journal of Political Economy 76 (2): 169-217. doi:10.1086/259394.

Beckmann, N., and R. E. Wood. 2017. "Editorial: Dynamic Personality Science. Integrating BetweenPerson Stability and Within-Person Change." Frontiers in Psychology 8: 1486. doi:10.3389/ fpsyg.2017.01486.

Behncke, S., M. Frölich, and M. Lechner. 2010. "Unemployed and Their Caseworkers: Should They Be Friends or Foes?" Journal of the Royal Statistical Society 173 (1): 67-92. doi:10.1111/j.1467985X.2009.00600.x.

Benarrosh, Y. 2006. Recevoir les chômeurs à l'ANPE. L'institution entre don et contrat (Collection «Logiques sociales»). Paris: L'Harmattan.

Bloom, H. S., C. J. Hill, and J. A. Riccio. 2003. "Linking Program Implementation and Effectiveness: Lessons from a Pooled Sample of Welfare-to-Work Experiments." Journal of Policy Analysis and Management 22 (4): 551-575. doi:10.1002/pam.10154.

Brodkin, E. Z. 2011. "Policy Work: Street-Level Organizations Under New Managerialism.” Journal of Public Administration Research and Theory 21 (Suppl 2): i253-i277. doi:10.1093/jopart/ muq093.

Brodkin, E. Z. 2016. “The inside Story: Street-Level Research in the US and Beyond." In Understanding Street-Level Bureaucracy, edited by P. L. Hupe, M. J. Hill, and A. Buffat, 25-42. Bristol: University Press.

Bruhn, A., and M. Ekström. 2017. "Towards a Multi-Level Approach on Frontline Interactions in the Public Sector: Institutional Transformations and the Dynamics of Real-Time Interactions." Social Policy \& Administration 51 (1): 195-215. doi:10.1111/spol.12193.

Burby, R. J., and R. G. Paterson. 1993. "Improving Compliance with State Environmental Regulations." Journal of Policy Analysis and Management 12 (4): 753-772. doi:10.2307/3325349.

Caswell, D., and F. Larsen. 2017. "Frontline Work in the Delivery of Danish Activation Policies And How Governance, Organizational and Occupational Contexts Shape This." In Frontline Delivery of Welfare-to-Work Policies in Europe: Activating the Unemployed, edited by R. van Berkel, D. Caswell, and P. Kupka, Chapter 10. New York: Routledge.

Cheon, S. H., J. Reeve, and I. S. Moon. 2012. "Experimentally Based, Longitudinally Designed, Teacher-Focused Intervention to Help Physical Education Teachers Be More Autonomy Supportive Toward Their Students." Journal of Sport and Exercise Psychology 34 (3): 365-396. doi:10.1123/jsep.34.3.365.

Crocker, D. A., and I. Robeyns. 2010. “Capability and Agency.” In Amartya Sen, edited by C. Morris, 60-90. New York: Cambridge University Press.

Deci, E. L., and R. M. Ryan. 1985. Intrinsic Motivation and Self-Determination in Human Behavior. New York: Plenum.

Deci, E. L., and R. M. Ryan. 2000. "The 'What' and 'Why' of Goal Pursuits: Human Needs and the Selfdetermination of Behavior." Psychological Inquiry 11 (4): 227-268. doi:10.1207/ S15327965PLI1104_01.

Deci, E. L., and M. Vansteenkiste. 2004. "Self-Determination Theory and Basic Need Satisfaction: Understanding Human Development in Positive Psychology." Ricerche di Psichologia 27: 17-34.

Djuve, A. B., and H. C. Kavli. 2014. "Facilitating User Involvement in Activation Programmes: When Carers and Clerks Meet Pawns and Queens." Journal of Social Policy 44 (2): 235-254. doi:10.1017/S0047279414000804.

Doyal, L., and I. Gough. 1984. “A Theory of Human Needs.” Critical Social Policy 4 (10): 6-38. doi:10.1177/026101838400401002.

Dzimira, S. 2007. "Recevoir les chômeurs à l'ANPE : L'institution entre don et contrat." Revue du MAUSS permanente. www.journaldumauss.net/./?Recevoir-leschomeurs-a-l-ANPE.

Elmore, R. F. 1980. "Backward Mapping: Implementation Research and Policy Decisions.” Political Science Quarterly 94 (4): 601-616. doi:10.2307/2149628.

Etzioni, A. 1961. "Organizational Control Structure." In Handbook of Organizations, edited by J. March, 650-677. Chicago: Rand McNally.

Grasmick, H. G., and R. J. Bursik Jr. 1990. "Conscience, Significant Others, and Rational Choice: Extending the Deterrence Model." Law and Society Review 24 (3): 837-861. doi:10.2307/ 3053861.

Hasenfeld, Y. [1992] 2010. Human Services as Complex Organizations. Thousand Oaks: SAGE. 
Hill, M. J., and P. L. Hupe. 2003. “The Multi-Layer Problem in Implementation Research.” Public Management Review 5 (4): 471-490. doi:10.1080/1471903032000178545.

Hjörne, E., K. Juhila, and C. van Nijnatten. 2010. "Negotiating Dilemmas in the Practices of StreetLevel Welfare Work.” International Journal of Social Welfare 19 (3): 303-309. doi:10.1111/j.14682397.2010.00721.x.

Hupe, P. L., and A. Buffat. 2014. "A Public Service Gap: Capturing Contexts in a Comparative Approach of Street-Level Bureaucracy.” Public Management Review 16 (4): 548-569. doi:10.1080/ 14719037.2013.854401.

Hutter, B. M. 1989. “Variations in Regulatory Enforcement Styles.” Law and Policy 11 (2): 153-174. doi:10.1111/j.1467-9930.1989.tb00024.x.

Janssen, D. 2006. De dienstverlening van de VDAB en de rol van ICT: een vooronderzoek [The Service Delivery of VDAB and the Role of ICT: A Preliminary Study]. Leuven: Steunpunt Bestuurlijk Onderzoek Vlaanderen.

Lambert, M. J., and A. E. Bergin. 1994. "The Effectiveness of Psychotherapy." In Handbook of Psychotherapy and Behavior Change, 4th ed., edited by A. E. Bergin and S. L. Garfield, 143-189. New York: Wiley.

Le Grand, J. 1997. "Knights, Knaves or Pawns? Human Behaviour and Social Policy." Journal of Social Policy 26 (2): 149-169. doi:10.1017/S0047279497004984.

Lipsky, M. [1980] 2010. Street-Level Bureaucracy: Dilemmas of the Individual in Public Services. New York: Russell Sage Foundation.

May, P. J., and S. C. Winter. 1999. "Regulatory Enforcement and Compliance: Examining Danish Agro-Environmental Policy." Journal of Policy Analysis and Management 18 (4): 625-651.

May, P. J., and S. C. Winter. 2000. "Reconsidering Styles of Regulatory Enforcement: Patterns in Danish Agro-Environmental Inspection." Law \& Policy 22 (2): 143-173. doi:10.1111/14679930.00089.

May, P. J., and S. C. Winter. 2012. "Regulatory Enforcement Styles." In Explaining Regulatory Compliance, edited by C. Parker and V. L. Nielsen, 222-244. Cheltenham: Edwar Elgar.

McDonald, M., and G. Marston. 2005. "Workfare as Welfare: Governing Unemployment in the Advanced Liberal State." Critical Social Policy 25 (3): 374-401. doi:10.1177/0261018305054077.

Moore, P. J., A. E. Sickel, J. Malat, D. Williams, J. Jackson, and N. E. Adler. 2004. "Psychosocial Factors in Medical and Psychological Treatment Avoidance: The Role of the Doctor-Patient Relationship." Journal of Health Psychology 9 (3): 421-433. doi:10.1177/1359105304042351.

Muthén, L. K., and B. O. Muthén. [1998] 2017. Mplus User's Guide. 8th ed. Los Angeles: Muthén \& Muthén.

Nielsen, V. L. 2016. "Law Enforcement Behaviour of Regulatory Inspectors." In Understanding Street-Level Bureaucracy, edited by P. L. Hupe, M. J. Hill, and A. Buffat, 115-132. Bristol: University Press.

Pautz, M., S. Rinfret, and M. Rorie. 2017. "Understanding the Regulatory Thicket: Interactions among State Environmental Regulators and Regulatees." International Journal of Public Administration 40 (2): 101-114. doi:10.1080/01900692.2015.1076002.

Raykov, T. 2004. "Behavioral Scale Reliability and Measurement Invariance Evaluation Using Latent Variable Modeling." Behavior Therapy 35 (2): 299-331. doi:10.1016/S0005-7894(04)80041-8.

Reeve, J., M. Vansteenkiste, A. Assor, I. Ahmad, S. H. Cheon, H. Jang, H. Kaplan, J. D. Moss, B. S. Olaussen, and C. K. J. Wang. 2014. "The Beliefs that Underlie Autonomy-Supportive and Controlling Teaching: A Multinational Investigation.” Motivation and Emotion 38 (1): 93-110. doi:10.1007/s11031-013-9367-0.

Riccio, J., and Y. Hasenfeld. 1996. "Enforcing a Participation Mandate in a Welfare-to-Work Program.” Social Service Review 70 (4): 516-542. doi:10.1086/604214.

RStudio Team. 2015. RStudio: Integrated Development for R. Boston: RStudio. http://www.rstudio. $\mathrm{com} /$.

Ryan, R. M., M. F. Lynch, M. Vansteenkiste, and E. L. Deci. 2011. "Motivation and Autonomy in Counselling, Psychotherapy, and Behavior Change: A Look at Theory and Practice." The Counselling Psychologist 39 (2): 193-260. doi:10.1177/0011000009359313.

Schneider, A., and H. Ingram. 1990. "Behavioral Assumptions of Policy Tools." The Journal of Politics 52 (2): 510-529. doi:10.2307/2131904.

Sen, A. K. 1999. Development as Freedom. New York: Knopf. 
Soss, J., R. Fording, and S. F. Schram. 2011. "The Organization of Discipline: From Performance Management to Perversity and Punishment." Journal of Public Administration Research and Theory 21 (Suppl 2): i203-i232. doi:10.1093/jopart/muq095.

Struyven, L., and L. Van Parys. 2014. "Revisiting the Pillars of the PES and Common Challenges." In Building Bridges. Shaping the Future of Public Employment Services Towards 2020, edited by F. Leroy and L. Struyven, 49-69. Brugge: die Keure.

Toerien, M., R. Sainsbury, P. Drew, and A. Irvine. 2015. “Understanding Interactions between Social Security Claimants and Frontline Employment Advisers - Public and Private Provision in the UK." Social Work \& Society 13 (1): 1-21.

Tummers, L., V. Bekkers, and B. Steijn. 2009. "Policy Alienation of Public Professionals." Public Management Review 11 (5): 685-706. doi:10.1080/14719030902798230.

van Yperen, T., M. van der Steege, A. Addink, and L. Boendermaker. 2010. Algemeen en specifiek werkzame factoren in de jeugdzorg: stand van de discussie [General and Specific Active Ingredients in Youth Care: State of Affairs of the Debate]. Utrecht: Nederlands Jeugdinstituut.

Vandenabeele, W. 2007. "Toward a Public Administration Theory of Public Service Motivation." Public Management Review 9 (4): 545-556. doi:10.1080/14719030701726697.

Vansteenkiste, M., and K. M. Sheldon. 2006. “There's Nothing More Practical than a Good Theory': Integrating Motivational Interviewing and Self-Determination Theory." British Journal of Clinical Psychology 45 (1): 63-82. doi:10.1348/014466505X34192.

Vansteenkiste, M., J. Simons, W. Lens, B. Soenens, and L. Matos. 2005. "Examining the Motivational Impact of Intrinsic versus Extrinsic Goal Framing and Autonomy-Supportive versus Internally Controlling Communication Style on Early Adolescents' Academic Achievement." Child Development 76 (2): 483-501. doi:10.1111/j.1467-8624.2005.00858.x.

Vansteenkiste, M., and A. Van den Broeck. 2014. "Understanding the Motivational Dynamics among Unemployed Individuals: Refreshing Insights from the Self-Determination Theory Perspective." In The Oxford Handbook of Job Loss and Job Search, edited by U.-C. Klehe and E. A. J. van Hooft. doi:10.1093/oxfordhb/9780199764921.013.005.

Vermunt, J. K., and J. Magidson. 2009. "Latent Class Cluster Analysis." In Applied Latent Class Analysis, edited by J. A. Hagenaars and A. L. McCutcheon, 89-106. Cambridge: Cambridge University Press.

Weatherall, C. D., and K. S. Markwardt. 2010. Working Paper 4: Caseworker Behavior and Clients' Employability. Copenhagen: SFI. https://www.sfi.dk/publikationer/caseworker-behavior-and-cli ents-employability-4654/.

Winter, S. C. 1999. "Perspectives on Implementation Research: Responses to Lester and Goggin's 'Back to the Future'." Policy Currents 8 (4): 1-5.

Winter, S. C. 2003. "Political Control, Street-Level Bureaucrats and Information Asymmetry in Regulatory and Social Policies". Paper prepared for the annual meeting of the Association for Policy Analysis and Management, Washington, DC, November 6-8.

Winter, S. C., and P. J. May. 2001. "Motivation for Compliance with Environmental Regulations." Journal of Policy Analysis and Management 20 (4): 675-698. doi:10.1002/(ISSN)1520-6688.

Wood, A. L. 1974. Deviant Behavior and Control Strategies. Lexington: D. C. Heath.

Wright, S. E. 2012. "Welfare-to-Work, Agency and Personal Responsibility." Journal of Social Policy 41 (2): 309-328. doi:10.1017/S0047279411001000. 